\begin{tabular}{ccc}
\hline & International Journal of Engineering \& Technology, $7(2.14)(2018) 191-195$ \\
SPC & International Journal of Engineering \& Technology \\
Website www.sciencepubco.com/index.php/IJET & Research Paper \\
\hline
\end{tabular}

\title{
A study on university course and exam timetabling problems and methods: an optimization survey
}

\author{
Ahmad Firdaus Khair ${ }^{1}$ *, Mokhairi Makhtar ${ }^{1}$, Munirah Mazlan ${ }^{1}$, Mohamad Afendee Mohamed ${ }^{1}$, \\ Mohd Nordin Abdul Rahman ${ }^{1}$ \\ ${ }^{1}$ Faculty of Informatics and Computing, Universiti Sultan Zainal Abidin, 21300 Terengganu, Malaysia \\ *Corresponding author E-mail: firdauskhair@yahoo.com
}

\begin{abstract}
The objective of this paper was to retrieve the overview approaches that have been proposed and classification constraints related to previ-ous papers of timetabling problems. Optimisation and scheduling are essential problems in every type of timetabling that can be considered as a non-deterministic polynomial. The objective of this paper to investigate the course and exam timetabling problem by presented classifi-cation table of set of constraints and describes the most reliable method that has been used to solve university timetabling problem. The re-sult of study concerned the two most successfully method that widely used for optimising course and exam timetable. The contribution of this study also help to provide knowledge and idea for further surveys.
\end{abstract}

Keywords: Examination Timetabling; Scheduling; Ant Colony Optimization; Ant System; Optimization.

\section{Introduction}

For the past decade, numerous research papers have been published regarding time schedule which has always been considered as the nondeterministic polynomial-time hardness (NP-hard). This complication is vital for every educational resource and institution management. The course and exam timetabling is well known as time slot assignment for the course and exam schedule in almost every educational institution. Recently, each educational institution has its own feasible timetable of the course and exam orientation, which depends on how it manages the course and exam schedules. As a result, the researchers discovered several suitable approaches and effective solutions in order to deal with this kind of problem. Besides, many reviews of the literature on the timetabling for course and examinations have been carried out in order to find and distinguish the diversification ideas and knowledge from every researcher.

In order to present this paper, these literature research surveys were gathered and collected by using the Mendeley method to review the related selective information, articles, and knowledge of every previous researcher's approach. The World Wide Web browser was used to surf and find all the related studies about the timetabling problem and investigate the researchers' approach. Besides, various academic search engines were also utilised as the source of research such as Google Scholar, Springer, Mendeley, Science Direct and ResearchGate, among others which provided all the journal articles, books, papers and reports to be used in this paper survey. The purpose of this paper was to observe and get the overall information about the course and exam timetabling approaches and methods as well as the hard and soft constraints. Based on the classification structure, the reader will be able to get a better full review of each and every type of previous researchers' approach used in their papers.

In this paper, the course and examination timetabling issues will be briefly discussed followed by the literature references on con- straints and approaches. Therefore, the next segment will discuss the observation result overall graph and classification constraints before presenting a highlighted overall conclusion of the last section.

\section{The university course timetabling problem (UCTP)}

In this study, course timetabling (also known as a set of the meeting between students and lecturer for course studies) is considered as the university course timetabling problem (UCTP). It actually takes the event in an educational institution where the structure and construction are more complicated than school timetabling. Some surveys carried out found that the problem of this course timetabling was because of the allocation of limited resources. In addition, there were also two types of constraints that became the focus of the paper to clarify the constraint problem based on the survey of the literature. Therefore, every university has different problems and conflicts in managing their course timetable. In certain situation, facilities may also contribute to the course timetabling problem because there is a need to check the availability of rooms and also whether the rooms are able to accommodate the number of students so that they are comfortable during their lessons

The survey of literature also found that the time management for courses has a problem in time division for lecturers and students to get the suitable time to have classes or meetings. Moreover, some lecturers and students have different preferences points on their courses that lead to another constraint to the course timetable respectively. For the problem of course subjects, there will be some conflicts for certain students and lecturers their schedules when clash and overlap on the same day. Besides, a consecutive or nonstop course subject in a day might inflict fatigue on those students. From the previous literature, many approaches including method and techniques were utilized in order to overcome this UCTP. 


\section{The university examination timetabling problem (UCTP)}

University exam timetabling problem (UETP) was considered in this problem study. An overview of the literature showed that examination timetabling problem consists of time, rooms, examination subjects and student capacity. The room distribution is essential in every examination event to determine the capacity of the students that can be accommodated by the facilities. Typically, a room has its own facilities, for example, room space, seat capacity and the use of a room. It is difficult to choose a suitable room if the requirement is not satisfied by the examination event By using the appropriate method, deploying room search and selecting it is a good way to assign student groups on which type of room is available for their examination.

Exam timetabling also faces a problem with exam subject conflict, where more than one examination is conducted in the same slot on the same day. Due to this problem, students may not be able to take the examination that they enrolled in respectively. Moreover, every examination also can have its conditions and requirements that need to be associated with. The room and period preferences are prohibited in circumstances where exams were already assigned. In terms of time, it comprises all the set of duration, date and start or end time. If there is any violation of this set, it will lead to a problem in assigning the appropriate time for the students' exam.

To construct a feasible and complete timetable, fundamental elements of constraints also need to be considered. During the exam timetabling construction, it is required to satisfy numerous con- straints before assigning the examination events. For this study on UETP, two types of constraints were classified to distinguish between the hard and soft constraints.

\section{Hard constraints and soft constraints}

In the previous research and literature surveys, the definition of the two constraint cases in timetabling is similar and has the same signification. Therefore, there was no surprise on the constraints because every researcher came out with the same knowledge and idea about the course and examination timetabling. This is because every university around the world has its own timetable management construction. The first constraint was known as hard constraints or the First Order, which was described as absolutely true and there can be no violation of any situations, circumstances and conditions. The second constraint known as soft constraints or Second Order can be defined as a desire that needs to be satisfied in condition to ensure that there was a solution to overcome the hard constraints.

\section{Approach methods}

The survey found that there were numerous approaches and methods utilised by the previous researchers to overcome the course and exam timetabling problem. By referring to the literature, each method and approaches were categorised in the presented graph to ease the reviewers for viewing existing researchers approach.

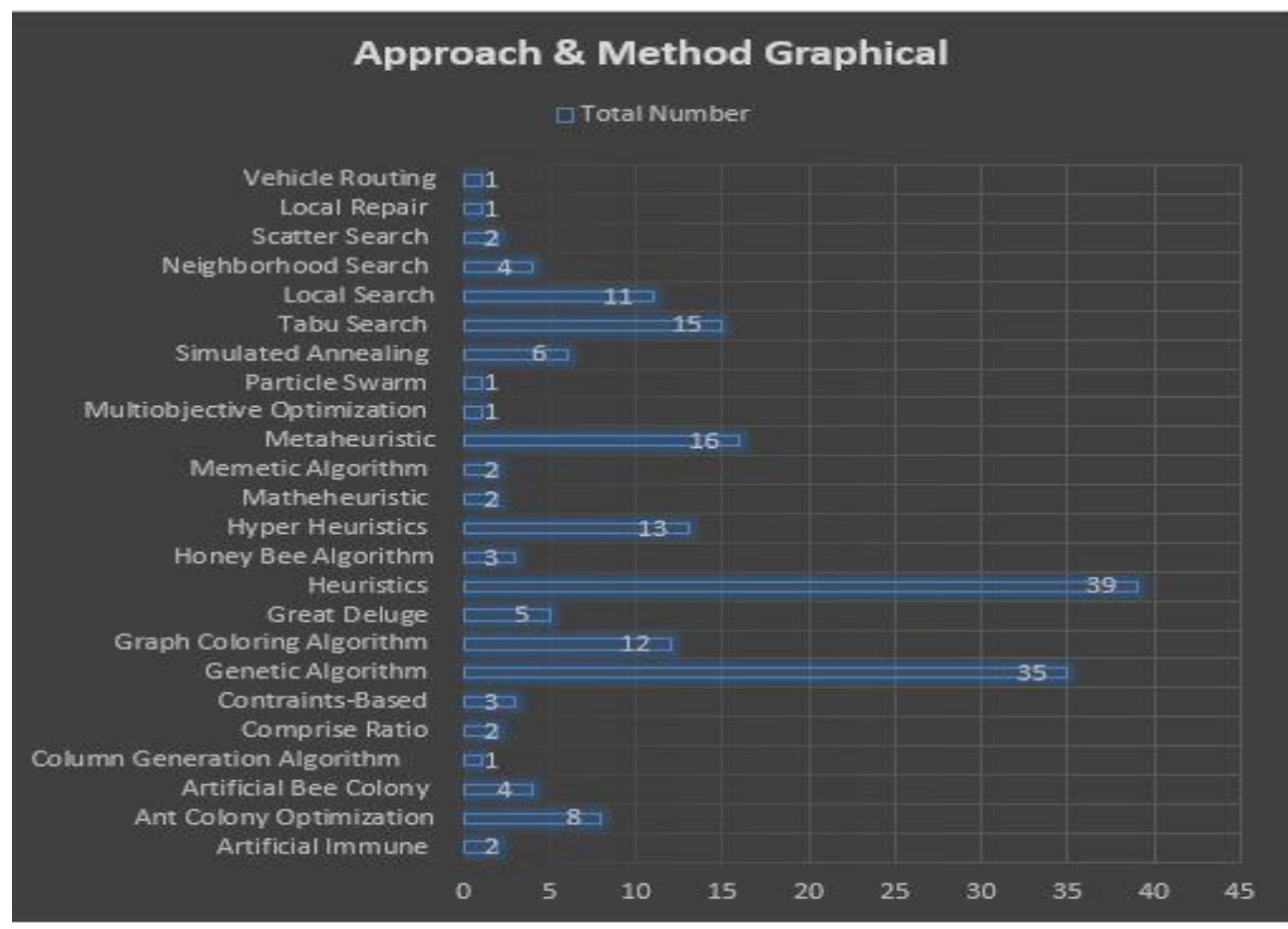

Fig. 1: Overall Total Graph Approach and Method.

\section{Discussion}

A classification of hard constraints and soft constraints and overall graph pattern for approaches and methods on the survey have been categorized from existing works. For this discussion, it concerning that two most reliable approaches and method are arranged according the highest result. Heuristics known to be highest one as it indicates about 39 of used then followed closely by genetic algorithm, which is 35 . It proved that both methods are effective to solve course and exam timetabling problem rather than others. An investigation also found out that the heuristic approach is to be believed effective in providing feasible solution, while genetic algorithm is better in producing optimal solution. Therefore, the good quality methods and approaches also need to consider both hard and soft constraints. Table 1 and 2 stated the classifications of hard and soft constraints for the course and examination timetabling. 
Table 1: Hard Constraints Classification

\begin{tabular}{|c|c|}
\hline Hard Constraints & References \\
\hline Lecturer/Teacher/Students cannot be in two places at the same time & $\begin{array}{l}{[1-2,10,13-14,18,20-21,23,25,27-30,34,36,38,44,49,51,54-56,58,} \\
61,65-66,68,72,75,81,84-85,90-92,100]\end{array}$ \\
\hline $\begin{array}{l}\text { No students can be assigned to more than one course/examinations at the } \\
\text { same time }\end{array}$ & $\begin{array}{l}{[3-7,9,12-13,15,17-34,36,38-41,45,47,49,54-56,58-61,64-65,72,74,} \\
79-87,89,91-96,99]\end{array}$ \\
\hline $\begin{array}{l}\text { Must not exceed the maximum capacity of a room and have sufficient } \\
\text { resources }\end{array}$ & {$[1,4-9,11-12,14,17-18,20]$} \\
\hline No student can sit for three consecutive exams on the same day & $\begin{array}{l}{[21-22,24,26-32,34-35,37-39,41-51,54,56-60,68,71,80,88-89,92,94-} \\
96,98-99]\end{array}$ \\
\hline $\begin{array}{l}\text { Each examination must be assigned to a single room and has at least one } \\
\text { invigilator or lecturer }\end{array}$ & $\begin{array}{l}{[4-5,15,21,34,40-41,47-48,51-53,55,59,61,73-75,81,85-88,90,92,96 \text {, }} \\
118,98,120-121]\end{array}$ \\
\hline $\begin{array}{l}\text { All course/exams must be scheduled and each exam must be scheduled at } \\
\text { only one time. }\end{array}$ & $\begin{array}{l}{[2,16,19,23-24,36,46,48,50,52,57,61,63,67,76,79,81-82,84-85,88,} \\
94]\end{array}$ \\
\hline $\begin{array}{l}\text { No student/lecturer/course/examination should be assigned to two or } \\
\text { more classes in one timeslot }\end{array}$ & {$[1,5-6,14,16,21,24,86,92]$} \\
\hline $\begin{array}{l}\text { Two lessons cannot be taught at the same time if a student group has to } \\
\text { attend both of them }\end{array}$ & {$[2,9,57,63,81,87]$} \\
\hline Courses that have the same teacher or class cannot overlap. & {$[8,10,38,47,65,70,76-78]$} \\
\hline $\begin{array}{l}\text { Students cannot enroll in two class event courses assigned to the same } \\
\text { timeslot. }\end{array}$ & {$[8,41,85,90]$} \\
\hline $\begin{array}{l}\text { Two courses and examinations with common students must be scheduled } \\
\text { in different timeslots. }\end{array}$ & {$[21,27,40,61,73,100]$} \\
\hline
\end{tabular}

Table 2: Soft Constraints Classification

\begin{tabular}{|c|c|}
\hline Soft Constraints & References \\
\hline $\begin{array}{l}\text { Minimize the number of students for two or more exams on consecu- } \\
\text { tive days }\end{array}$ & $\begin{array}{l}{[3-9,11-13,17-22,27,29,39-40,55-56,64,67-69,72,76,85,87,92,94-95,} \\
99]\end{array}$ \\
\hline $\begin{array}{l}\text { Minimize the number of students sitting for two exams in a room on } \\
\text { the same day }\end{array}$ & $\begin{array}{l}{[3,5-7,12-13,15,17-22,27,29,30-32,34,43,51,79,67-69,72,86,92,94-95 \text {, }} \\
99]\end{array}$ \\
\hline $\begin{array}{l}\text { Students should not attend three or more events in successive time } \\
\text { slots }\end{array}$ & {$[4,6,10-11,14,64,96,99]$} \\
\hline Spread out exams/course over time slots & $\begin{array}{l}{[1,7,11-12,15-18,21,24-25,30-35,38,43,46,54,56,58-59,63,65,67,73-} \\
74,79-80,84-85,88,93,95,98,100]\end{array}$ \\
\hline Large exams should be scheduled early in the timetable & $\begin{array}{l}{[9][12][17][18][20][21][23][25][30][39][49][55][56][51][65][67][81]} \\
{[82][84][91]}\end{array}$ \\
\hline $\begin{array}{l}\text { For each lecture, the number of students attending the course should } \\
\text { not be greater than the capacity }\end{array}$ & t \\
\hline $\begin{array}{l}\text { Students should not attend three or more events in successive time } \\
\text { slots }\end{array}$ & {$[4,6,10-11,14,53,96,99]$} \\
\hline $\begin{array}{l}\text { The lectures of a course should be spread into the given minimum } \\
\text { number of days }\end{array}$ & {$[53,57,50,63,97]$} \\
\hline
\end{tabular}

\section{Conclusion}

Based on the overall survey of the study, the graph of approaches and methods reveal that the methods of heuristics and genetic algorithm are the most reliable and preferred by the previous researchers work in order to optimize and solve the course and exam timetabling problem. As explained earlier, the investigation has been carried out to provide the knowledge and information for further use, especially for the development course and exam timetabling. The methods and classification of hard and soft constraints on timetabling problem is presented in this paper might contribute requirements and needs for any researcher's.

\section{Acknowledgement}

This work is partially supported by UniSZA (Grant RR008 CRIM/2016).

\section{References}

[1] E. A. Abdelhalim and G. A. El Khayat, "A Utilization-based Genetic Algorithm for Solving the University Timetabling Problem (UGA)," Alexandria Eng. J., vol. 55, no. 2, pp. 1395-1409, 2016.

[2] S. Abdennadher and M. Marte, "University course timetabling using constraint handling rules," Appl. Artif. Intel. vol. 14, no. 4, pp. 311-325, 2000.

[3] S. Abdul Rahman, A. Bargiela, E. K. Burke, E. Özcan, B McCollum, and P. McMullan, "Adaptive linear combination of heuristic orderings in constructing examination timetables," Eur. J. Oper. Res., vol. 232, no. 2, pp. 287-297, 2014.

[4] S. Abdullah, "Heuristic Approaches for University Timetabling Problems," no. June, p. 226, 2006.

[5] S. Abdullah, E. K. Burke, and B. Mccollum, "An investigation of variable neighbourhood search for university course timetabling," Proc. 2nd Multi-disciplinary Interna- tional Conf. Sched. Theory Appl., pp. 413-427, 2005.

[6] S. Abdullah and H. Turabieh, "Generating University Course Timetable Using Genetic Algorithms and Local Search," in 2008 Third International Conference on Convergence and Hybrid Information Technology, 2008, vol. 1, pp. 254-260.

[7] R. Abounacer et al., "A hybrid Ant Colony Algorithm for the exam timetabling problem to cite this version: A hybrid Ant Colony Algorithm for the exam timetabling problem," vol. 12, pp. 15-42, 2016.

[8] A. O. Adewumi, B. A. Sawyerr, and M. Montaz Ali, "A heuristic solution to the university timetabling problem," Eng. Comput., vol. 26, no. 8, pp. 972-984, Nov. 2009.

[9] A. Akbulut and G. Y1lmaz, "University Exam Scheduling System Using Graph Coloring Algorithm and RFID Technology," Int. J. Innov. Manag. Technol., vol. 4, no. 1, pp. 66-72, 2013.

[10] S. M. Al-yakoob and H. D. Sherali, "Computers \& Operations Research Mathematical models and algorithms for a high school timetabling problem," Comput. Oper. Res., vol. 61, pp. 56-68, 2015.

[11] R. Alvarez-Valdés, E. Crespo, and J. M. Tamarit, "A tabu search algorithm to schedule university examinations," Qüestiió, vol. 21, no. 2, pp. 201-215, 1997.

[12] M. Alzaqebah and S. Abdullah, "Artificial bee colony search algorithm for examination timetabling problems," vol. 6 , no. 17, pp. 4264-4272, 2011.

[13] P. Amaral and T. Cardal, "Computers \& Operations Research Compromise ratio with weighting functions in a Tabu Search multi- 
criteria approach to examination timetabling \$," Comput. Oper. Res., vol. 72, pp. 160-174, 2016.

[14] T. Arbaoui, J.-P. Boufflet, and A. Moukrim, "A matheuristic for exam timetabling," IFAC-PapersOnLine, vol. 49, no. 12, pp. 1289$1294,2016$.

[15] H. Asmuni, E. K. Burke, J. M. Garibaldi, B. McCollum, and A. J. Parkes, "An investigation of fuzzy multiple heuristic orderings in the construction of university examination timetables," Comput. Oper. Res., vol. 36, no. 4, pp. 981-1001, 2009

[16] E. Aycan and T. Ayav, "Solving the Course Scheduling Problem Using Simulated Annealing," no. March, pp. 6-7, 2009.

[17] M. Ayob, S. Abdullah, and A. Malik, "A practical examination timetabling problem at the Universiti Kebangsaan Malaysia," Int. J. Comput. ..., vol. 7, no. 9, pp. 198-204, 2007.

[18] M. Ayob et al., "Intelligent Examination Timetabling Software," Procedia - Soc. Behav. Sci., vol. 18, pp. 600-608, 2011.

[19] Z. N. Azimi, "Comparison of metaheuristic algorithms for Examination Timetabling Problem," J. Appl. Math. Comput., vol. 16, no. 1-2, pp. 337-354, Mar. 2004.

[20] M. Bader-El-Den, R. Poli, and S. Fatima, "Evolving timetabling heuristics using a grammar-based genetic programming hyperheuristic framework," Memetic Comput., vol. 1, no. 3, pp. 205-219, Nov. 2009.

[21] H. Belhaouari and F. Peschanski, "A Constraint Logic Programming Approach to Automated Testing," 24th Int. Conf. Log. Program, vol. 5366, pp. 754-758, 2008.

[22] A. L. aro Bolaji, A. T. Khader, M. A. Al-Betar, and M. A. Awadallah, "University course timetabling using hybridized artificial bee colony with hill climbing optimizer," J. Comput. Sci., vol. 5, no. 5, pp. 809-818, 2014.

[23] P. Taylor et al., "A time-predefined local search approach to exam timetabling problems A time-predefined local search approach to exam timetabling problems," no. October 2014, pp. 37-41.

[24] E. Burke, Y. Bykov, and S. Petrovic, "A Multicriteria Approach to Examination Timetabling," Springer Berlin Heidelberg, 2001, pp. 118-131.

[25] E. Burke, D. Elliman, P. Ford, and R. Weare, "Examination timetabling in British universities: A survey," 1996, vol. 1153, pp. 76-90.

[26] E. K. Burke, G. Kendall, M. Misir, and E. Özcan, "Monte Carlo hyper-heuristics for examination timetabling," Ann. Oper. Res., vol. 196, no. 1, pp. 73-90, 2012.

[27] E. K. Burke, G. Kendall, and E. Soubeiga, "A Tabu-Search Hyperheuristic for Timetabling and Rostering," J. Heuristics, vol. 9, no 6, pp. 451-470, Dec. 2003.

[28] E. K. Burke and J. P. Newall, "Solving Examination Timetabling Problems through Adaptation of Heuristic Orderings."

[29] E. K. Burke, S. Petrovic, and R. Qu, "Case-based heuristic selection for timetabling problems," J. Sched., vol. 9, no. 2, pp. 115-132, Apr. 2006.

[30] E. K. Burke, R. Qu, and A. Soghier, "Adaptive selection of heuristics for improving exam timetables," Ann. Oper. Res., vol. 218, no. 1, pp. 129-145, 2014.

[31] M. Caramia, P. Dell'Olmo, and G. F. Italiano, "New Algorithms for Examination Timetabling," Springer, Berlin, Heidelberg, 2001, pp. 230-241.

[32] M. W. Carter, "OR Practice-A Survey of Practical Applications of Examination Timetabling Algorithms," Oper. Res., vol. 34, no. 2, pp. 193-202, Apr. 1986

[33] R.-M. Chen and H.-F. Shih, "Solving University Course Timetabling Problems Using Constriction Particle Swarm Optimization with Local Search," Algorithms, vol. 6, no. 2, pp. 227-244, 2013.

[34] M. Chiarandini, M. Birattari, K. Socha, and O. Rossi-doria, "An effective hybrid algorithm for university course timetabling," pp. 403-432, 2006.

[35] P. H. Corr, B. Mccollum, M. A. J. Mcgreevy, and P. Mcmullan, “A New Neural Network Based Construction Heuristic for the Examination Timetabling Problem," Parallel Probl. Solving from NaturePPSN IX, pp. 392-401, 2006.

[36] M. Čupić, M. Golub, and D. Jakobović, "Exam timetabling using genetic algorithm," in Proceedings of the International Conference on Information Technology Interfaces, ITI, 2009, pp. 357-362.

[37] P. David, "A constraint-based approach for examination timetabling using local repair techniques," in Practice and Theory of Automated Timetabling II, 1998, pp. 169-186.

[38] P. De Causmaecker, P. Demeester, and G. Vanden Berghe, "A decomposed metaheuristic approach for a real-world university timetabling problem," Eur. J. Oper. Res., vol. 195, no. 1, pp. 307-318, 2009

[39] P. Demeester, B. Bilgin, P. De Causmaecker, and G. Vanden Berghe, "A hyperheuristic approach to examination timetabling problems: benchmarks and a new problem from practice," J. Sched., vol. 15 , no. 1, pp. 83-103, Feb. 2012.

[40] L. Di Gaspero and A. Schaerf, "Tabu search techniques for EXAMINATION TIMETABLING,” 2001, vol. 2079 LNCS, pp. 104-117.

[41] V. Dino Matija? G. Molnar, M.?upi??, D. Jakobovi??, and B. Dalbelo Ba??i??, "University course timetabling using ACO: A case study on laboratory exercises," Lect. Notes Comput. Sci. (including Subser. Lect. Notes Artif. Intell. Lect. Notes Bioinformatics), vol 6276 LNAI, no. PART 1, pp. 100-110, 2010.

[42] O. R. Doria and B. Paechter, "A memetic algorithm for University Course Timetabling," pp. 1-8, 2003.

[43] M. Doulaty, M. R. F. Derakhshi, and M. Abdi, "Timetabling: A State-of-the-Art Evolutionary Approach," Int. J. Mach. Learn. Comput., vol. 3, no. 3, pp. 255-258, 2013.

[44] O. El Mahdi, R. N. Ainon, and R. Zainuddin, "Using a Genetic Algorithm optimizer tool to generate good quality timetables," 2003 vol. 3, pp. 1300-1303.

[45] M. Eley, "Ant Algorithms for the Exam Timetabling Problem," in Practice and Theory of Automated Timetabling VI, Berlin, Heidelberg: Springer Berlin Heidelberg, 2006, pp. 364-382.

[46] A.R.Mirzaei and F.Djannaty, "Enhancing Max-Min Ant System for Examination Timetabling Problems," Int. J. Soft Comput., pp. 230 238, 2008.

[47] W. Erben, "A Grouping Genetic Algorithm for graph colouring and exam timetabling," 2001, vol. 2079 LNCS, pp. 132-156.

[48] W. Erben and J. Keppler, "A Genetic Algorithm Solving a Weekly Course- Timetabling Problem," 1995.

[49] W. Erben and P. Y. Song, "A Hybrid Grouping Genetic Algorithm for Examination Timetabling 2 The Hybrid Grouping Genetic Algorithm," no. 1, 2004.

[50] G. H. G. Fonseca, H. G. Santos, and E. G. Carrano, "Integrating matheuristics and metaheuristics for timetabling," Comput. Oper. Res., vol. 74, pp. 108-117, Oct. 2016.

[51] F. Zhaohui and A. Lim, "Heuristics for the Exam Scheduling Problem," pp. 172-175, 2000.

[52] D. Hadjidj and H. Drias, "A hybrid grasp and scatter search for the exam timetabling problem," 2010, pp. 297-302.

[53] A. Hertz, "Tabu search for large scale timetabling problems," Eur. J. Oper. Res., vol. 54, no. 1, pp. 39-47, Sep. 1991.

[54] W. K. Ho, A. Lim, and W. C. Oon, "Maximizing paper spread in examination timetabling using a vehicle routing method," 2001, pp. 359-366.

[55] M. Hosny and M. Al-Olayan, "A mutation-based genetic algorithm for room and proctor assignment in examination scheduling," in 2014 Science and Information Conference, 2014, pp. 260-268.

[56] B. Hussin, A. S. H. Basari, A. S. Shibghatullah, S. A. Asmai, and N. S. Othman, "Exam timetabling using graph colouring approach," in 2011 IEEE Conference on Open Systems, 2011, pp. 133-138.

[57] S. Innet, "A Noval Approach of Genetic Algorithm for Solving Examination Timetabling Problems," pp. 233-237, 2013

[58] S. K. Jha, "Exam Timetabling Problem using Genetic Algorithm," Int. J. Res. Eng. Technol., vol. 3, no. 4, pp. 649-654, 2014.

[59] M. N. M. Kahar and G. Kendall, "The examination timetabling problem at Universiti Malaysia Pahang: Comparison of a constructive heuristic with an existing software solution," Eur. J. Oper. Res. vol. 207, no. 2, pp. 557-565, 2010.

[60] C. B. Kalayci, "Model Focusing on Student Success for the Case of the College of Engineering at Pamukkale University, Turkey," vol. 25, no. 1, pp. 137-153, 2012.

[61] M. Karova, "Solving timetabling problems using genetic algorithms," in 27th International Spring Seminar on Electronics Technology: Meeting the Challenges of Electronics Technology Progress, 2004., 2004, vol. 1, no. 7, pp. 96-98.

[62] S. K. Ibraheem and A. Q. Ansari, "Ant colony optimization : A tutorial," MR Int. J. Eng. Technol., vol. 7, no. 2, pp. 35-41, 2015.

[63] Z. L? In addition, J. K. Hao, "Solving the course timetabling problem with a hybrid heuristic algorithm," Lect. Notes Comput. Sci. (including Subser. Lect. Notes Artif. Intell. Lect. Notes Bioinformatics), vol. 5253 LNAI, pp. 262-273, 2008

[64] R. Lewis and B. Paechter, "Application of the Grouping Genetic Algorithm to University Course Timetabling," 2002.

[65] A. Lim, J. Ang, W. Ho, and W. Oon, "UTTSExam: A CampusWide University Exam-Timetabling System," Natl. Conf. Artif. Intell., pp. 838-844, 2002.

[66] Z. Lü and J. K. Hao, "Adaptive Tabu Search for course timetabling," vol. 200, no. 1, pp. 235-244, Jan. 2010.

[67] N. Mansour, V. Isahakian, and I. Ghalayini, "Scatter search technique for exam timetabling," Appl. Intell., vol. 34, no. 2, pp. 299 310, Apr. 2011. 
[68] B. McCollum, P. McMullan, A. J. Parkes, E. K. Burke, and S. Abdullah, "An extended great deluge approach to the examination timetabling problem," Proc. 4th Multidiscip. Int. Conf. Sched. Theory Appl., no. August, pp. 424-434, 2009.

[69] I. Méndez-Díaz, P. Zabala, and J. J. Miranda-Bront, “An ILP based heuristic for a generalization of the post-enrollment course timetabling problem,' Comput. Oper. Res., vol. 76, pp. 195-207, 2016.

[70] V. Beldi, "Timetabling through Constrained Heuristic Search and Genetic Algorithms," vol. 26, no. March 1995, 1996.

[71] T. Müller, "Real-life Examination Timetabling."

[72] Z. N. Azimi, "Hybrid heuristics for Examination Timetabling problem," vol. 163, pp. 705-733, 2005.

[73] C. Nothegger, A. Mayer, A. Chwatal, and G. R. Raidl, "Solving the post enrolment course timetabling problem by ant colony optimization,” Ann. Oper. Res., vol. 194, no. 1, pp. 325-339, 2012.

[74] R. Burke, Edmund and MacCloumn, Barry and Meisels, Amnon and Petrovic, Sanja and Qu, "A Graph-Based Hyper-Heuristic for Educational Timetabling Problems," vol. 176, pp. 177-192, 2007.

[75] O. S. O, F. T. M, O. E. O, and O. A. C, "Hybrid MetaHeuristic Feature Extraction Technique for Solving Timetabling Problem," Int. J. Sci. Eng. Res., vol. 3, no. 8, pp. 1-6, 2012.

[76] E. Ozcan and A. Alkan, "Timetabling using a steady state genetic algorithm," fourth Int. Conf. Pract. Theory Autom. Timetabling, 2002.

[77] E. Özcan and A. Alkan, "A Memetic Algorithm for Solving a Timetabling Problem: An Incremental Strategy," Computer (Long. Beach. Calif). pp. 394-401, 2007.

[78] S. Petrovic and Y. Bykov, "A Multiobjective Optimisation Technique for Exam Timetabling Based on Trajectories."

[79] N. Pillay, "Evolving hyper-heuristics for the uncapacitated examination timetabling problem," J. Oper. Res. Soc., vol. 63, no. 1, pp. 47-58, Jan. 2012.

[80] N. Pillay, A review of hyper-heuristics for educational timetabling. 2014.

[81] N. Pillay and W. Banzhaf, "An informed genetic algorithm for the examination timetabling problem," Appl. Soft Comput., vol. 10, no. 2, pp. 457-467, Mar. 2010.

[82] R. Qu, E. K. Burke, and B. Mccollum, "Adaptive Automated Construction of Hybrid Heuristics for Exam Timetabling and Graph Colouring Problems 1 Introduction 2 Benchmark Exam Timetabling and Graph Colouring Problems," pp. 1-19.

[83] L. P. Reis and E. Oliveira, "A language for specifying complete timetabling problems," Lect. Notes Comput. Sci. (including Subser. Lect. Notes Artif. Intell. Lect. Notes Bioinformatics), vol. 2079 LNCS, pp. 322-341, 2001.

[84] P. Ross, E. Hart, D. Corne, F. Hill, and E. Eh, "Some observations about GA-based exam timetabling 1 Introduction 2 The representation," vol. 2, no. August 1997, pp. 1-16, 1998.

[85] P. Ross, E. Prossnapieracuk, J. G. Marin-blizquez, and E. Hart "Hyper-heuristics applied to Class and Exam Timetabling problems," 2003.

[86] N. R. Sabar, M. Ayob, R. Qu, and G. Kendall, "A graph coloring constructive hyper-heuristic for examination timetabling problems," Appl. Intell., vol. 37, no. 1, pp. 1-11, Jul. 2012.

[87] B. Sigl, M. Golub, and V. Mornar, "Solving timetable scheduling problem using genetic algorithms," Proc. 25th int. conf. ..., pp. 519-524, 2003.

[88] E. S. Sin, "REINFORCEMENT LEARNING WITH EGD BASED HYPER HEURISTIC SYSTEM FOR EXAM," in IEEE CCIS, 2011, pp. 462-466.

[89] A. Soghier and R. Qu, "Adaptive selection of heuristics for assigning time slots and rooms in exam timetables," Appl. Intell., vol. 39, no. 2 , pp. 438-450, Sep. 2013.

[90] J. A. Soria-Alcaraz, G. Ochoa, J. Swan, M. Carpio, H. Puga, and E. K. Burke, "Effective learning hyper-heuristics for the course timetabling problem," Eur. J. Oper. Res., vol. 238, no. 1, pp. 77-86, 2014.

[91] R. Burke, Edmund and Dror, Moshe and Petrovic, Sanja and Qu, "Hybrid Graph Heuristics within a Hyper-heuristic Approach to Exam Timetabling Problems," vol. 9, pp. 79-91, 2005.

[92] N. D. Thanh, "Solving Timetabling Problem Using Genetic and Heuristic Algorithms," in Eighth ACIS International Conference on Software Engineering, Artificial Intelligence, Networking, and Parallel/Distributed Computing (SNPD 2007), 2007, vol. 3, pp. 472 477.

[93] T. Thepphakorn and P. Pongcharoen, "Heuristic ordering for ant colony based timetabling tool," 2012, vol. 4, pp. 87-96.

[94] J. M. Thompson and K. A. Dowsland, "A robust simulated annealing based examination timetabling system," Comput. \&amp; Oper. Res., vol. 25, no. 7-8, pp. 637-648, 1998.
[95] H. T. Ã and S. Abdullah, "An integrated hybrid approach to the examination timetabling problem," Omega, vol. 39, no. 6, pp. 598 607, 2011.

[96] B. M. Abdullah, Salwani, Edmund K.Burke, "A hybrid Evoluationary Appraoch to the University Course Timetabling Problem," IEEE Congr., pp. 1764-1768, 2007.

[97] R. Willemen, School timetable construction; algorithms and complexity. 2002.

[98] G. Woumans, L. De Boeck, J. Beliën, and S. Creemers, “A column generation approach for solving the examination-timetabling problem,” Eur. J. Oper. Res., vol. 253, no. 1, p. 17, 2016.

[99] S. Yang and S. N. Jat, "Genetic algorithms with guided and local search strategies for university course timetabling," IEEE Trans. Syst. Man Cybern. Part C Appl. Rev., vol. 41, no. 1, pp. 93-106, 2011.

[100] J. Yellen, R. College, and E. K. Burke, "Linear Combinations of Heuristics for Examination Timetabling," vol. 194, pp. 89-109, 2012. 